\title{
The Anglo-American Paradigm: Lost and Found in Current Theology
}

\section{Jerome A Stone \\ William Rainey Harper College, Illinois}

\begin{abstract}
The main Western paradigm involves: 1) dichotomous thinking, 2) valuing abstraction and stability, 3) the quest for certainty, 4) search for foundations and proper method, and 5) a precise language. Postmodernism often favors the mirror images of these five. There is a third approach in many Anglo-American writers which involves neither alternatives. This article analyzes four contemporary theologians, two of whom, Mark C Taylor and George Lindbeck, are rooted in the newer tradition and two, Phil Hefner and Delwin Brown, in the Anglo-American. This essay may be considered a plea to avoid the traditionalpostmodern dichotomy.
\end{abstract}

\section{INTRODUCTION}

The dominant Western paradigm has involved: 1) dichotomies (self/other, nature/freedom, mind/body, etc), 2) a valuing of abstraction and stability, 3) the quest for certainty, 4) a search for foundations and proper method, and 5) a precise language. An alternative approach, including Nietzsche, Heidegger; and post-structuralists, developed counter-themes: 1) an overthrow of dichotomies, 2) a focus on the particular and transitory, 3) a recogaition of uncertainty, antifoundationalism and antimethodologism, and 5) a polyvalent language. Since these are the mirror images of the first set of themes, they support, ironically, the dichotomous tendency of Western thought.

There is a third approach, found in many American and British writers (and a few Europeans) including pragmatists, process thinkers, and Wittgenstein. This approach is an advance beyond the older Western tradition without falling into the excesses of the new Continental paradigm. Many contemporary thinkers ignore this approach at their peril. Their position should be strengthened if they could argue showing that their thought is more adequate than this Anglo-American approach. By ignoring it and concentrating on the rejecting of the older paradigm, their arguments involve a false dichotomy. At worst their positions suffer from the excesses of a one-sided rejection of an old viewpoint and fail to draw from the resources of the Anglo-American approach. 
This paper is an analysis and evaluation, in terms of the five mirror images of the older Western paradigm, of four contemporary theologians, two, Mark C. Taylor and George Lindbeck, rooted in the newer European tradition and two, Philip Hefner and Delwin Brown, in the Anglo-American. The evaluation is from a viewpoint appreciative of the Anglo-American approach.

Lindbeck has a false dichotomy between the intra- aad extrasemiotic references of language, allowing him to downplay the reference of religious language beyond itself. $\mathrm{He}$ also has a false split between 'inner' experience and cultural symbols. (In personal correspondence Professor Lindbeck has disagreed with my interpretation of him. Without going into a detailed rebuttal of his letter, perhaps it is fair to say that our paradigm differences influence our differing exegeses of his text. This should cause some cognitive discomfort but should not be surprising.)

Taylor rejects the ontotheological tradition but his only option left is an extreme opposite postmodern view deconstructing God, self, history, and 'the' book'.

Hefner's theory of the created co-creator is evolutionary at its core and is a sustained move beyond traditioaal dichotomies, involving falsifiable and tentative hypotheses which avoid the highest levels of abstraction. Although he is close to a foundationalist reliance on genetics and biology, his interplaying of science, myth, and theology finally refuses to privilege any one discourse and valorizes both myth and discursive language.

Central to Brown's constructive historicism is a notion of culture's canon as a polyphonic collection of fluid and diverse meanings, yet specific enough so that individual and communal identities may be negotiated within its field. He develops a revisionary and publicly debatable option beyond the essentialism of many conservative and liberal theologies and the anti-essentialism of many radical and deconstructive theologies.

\section{GEORGE LINDBECK}

In The Nature of Doctrine Lindbeck is trying to develop and defend a cultural-linguistic theory of religion and doctrine in which doctrines are to be seen as primarily secondorder statements, as regulations or rules governing (but not specifying) religious affirmations. He proposes this theory as an alternative to the traditional theory in which religious language is basically propositional and to the liberal's experiential-expressive theory in which doctrines are expressive symbols of an inner religious experience.

According to Lindbeck's cultural-linguistic theory, religions are 'comprehensive interpretive schemes, usually embodied in myths or narratives and heavily ritualized, which structure human experience and understanding of self and world' and which are used for the intention of 'identifying and describing what is taken to be "more important than anything else in the universe" and to organizing all of life, including both 
behavior and beliefs, in relation to this'. To become religious, on this view, is to interiorize a set of skills by training and practice. To put it slightly differently, a religion is a communal phenomenon shaping the subjectivities of the individual, not a manifestation of them (Lindbeck 1984:32-33).

A key issue for Lindbeck is whether religion should be seen as the product of the experience of the divine (the experiential-expressive theory) or whether, as he claims, religion produces the experience. Lindbeck briefly grants that there is a reciprocity between 'inner' experience and 'external' religious and cultural factors and claims merely to stress the latter as the primary factors (Lindbeck 1984:30-34).

However, in his working out of the thesis he drops the recognition that there is an interplay between the 'inner' experience and the communal-linguistic network of symbols and instead lays exclusive emphasis on the social network when he works out his analysis. Indeed, Lindbeck is quite explicit about the exclusiveness of his emphasis on the symbolic network, despite his brief disclaimer about the interplay of the 'inner' and the 'outer'. Since symbol systems are primary, there are no uninterpreted or unthematized experiences. For Lindbeck an experience, by definition, is something of which one is conscious, a key difference from radical empiricism which is willing to speak of emergent meanings, vague feelings, and a penumbra surrounding conscious clarity. An experience, further, depends on its being symbolized, and all symbol systems have their origin in interpersonal relations and social interactions. Lindbeck suggests that there are no purely private symbolizations and therefore no private experiences, or, as a less strong and perhaps more defensible claim, that it is not necessary to utilize the hypothesis of private experience in order to understand religion (Lindbeck 1984:36-37.

He has, in short, become trapped in a dichotomy between 'inner' experience and 'outer' religious and cultural factors. A more adequate approach would maintain, using Lindbeck's terms, that there is an interplay between 'inner' experience and 'outer' religious and cultural factors. To use terms which I prefer, there is an interplay between the social network of symbolized experience and the individual creative use of it in explaining one's own experience. Further, by not recognizing the transactions between symbols and the world, Lindbeck has no room for the exploration of the world through a disciplined and open sensitive discernment. It would be difficult to say which has primacy, the personal or the social, nor is it important to do this. However, Lindbeck has not made a strong case for his denial of the significance of the personal.

In Lindbeck's theory, religious language is intratextual or intrasemiotic, that is, it is a second-order language. It says nothing either true or false about the object of religious language, about God, for example (Lindbeck 1984:68-69). Lindbeck says that this cultural-linguistic theory does not emply a rejection of epistemological realism, since theology and doctriae are second-order language. But this intrasemiotic approach in effect means that the extrasemiotic relationship can be ignored. 
Lindbeck wishes to avoid the alternative of relativism and foundationalism. However, intratextuality seems relativistic, turning religion into incommensurable intellectual ghettoes and leaving the choice between religions arbitrary, since there is no foundation from which to evaluate competing claims. But Lindbeck wishes to assert that the antifoundationalism which is a corollary of his approach is not identical with irrationalism.

Lindbeck suggests that we have learned from Kuhn and Wittgenstein that the norms of reasonableness are too rich and subtle to be specified in a general theory. Rather reasonableness is analogous to the unformalizable skill of the arts or the linguistically competent. Intelligibility and credibility come from competence in a skill, not from a theory. Corning to believe is parallel to learning a language. One does not use argumentation in learning a language, but once one has learned to speak the language, argument becomes possible. Thus while religious language is invulnerable to definitive confirmation and refutation, it can be argued for' (Lindbeck 1984:130-132).

Such arguments will not involve which theory of the Trinity, for example, best corresponds to the real nature of God. No one can answer that question. Rather the best theory of the Trinity will be the one that best organizes the data of Scripture and tradition with a view to its use in worship and life. In other words for Lindbeck confirmation and disconfirmation of religious assertions occurs through the accumulation of successes or failures in making coherent sense of relevant data (Lindbeck 1984: 106, 131). Again Lindbeck is caught ia a false dilemma. Either we have conclusive proof or no arguments at all. However, while we do not have 'no doubt about it' confirmation and 'knock down' refutation, surely there is a middle ground in which we can provide good, if not conclusive, arguments for our positions.

\section{MARK TAYLOR}

Recently Mark C Taylor has been developing what he calls an 'A/theology', in which he attempts to think about religious issues after the 'death of God'. Taylor seems to have taken as his starting point the position of Dostoevsky's Ivan Karamozov that without God everything is permitted. The trouble is that Taylor does not seem to have examined the dichotomy involved here: either God exists or else everything is permitted. Without God as traditionally conceived is, indeed, everything permitted?

In his postmodern a/theology, Taylor's argument assumes a dichotomy between the ontotheological perspective, from Augustine to Hegel, and a postmodern viewpoint which moves to the opposite extreme. Since Taylor deconstructs the former notion, he is left with the opposite alternative. As often happens with dichotomies, this one turns out to be false. More choices are available than the two considered. There is for example, an entire range of options clustered around both the process viewpoints and 
the related positions of radical empiricism. It is surprising that Taylor does not consider these options, siace he delineates a process-relational view in chapters 3 and 4 of Deconstructing Theology'. My critique is that there are alternatives to both the ontotheological tradition which he rightly rejects and the extreme a/theological view which he espouses.

Taylor starts with a rejection of classical theism. He identifies the God of classical theism as the transcendent and eternal First Cause.

According to the tenets of classical theism, God, who is One, is the supreme Creator, who, through the meditation of His divine Logos, brings the world into being and providentially directs its course. This Primal Origin (First Cause or Arche) is also the Ultimate End (Final Goal or Telos) of the world. Utterly transcendent and thoroughly eternal, God is represented as totally present to Himself [sic]. He is, in fact, the omnipresent fount, source, ground, and uncaused cause of presence itself.

(Taylor 1984:7)

Taylor's world view is based on the contrast he perceives between the traditional ontotheology of classical theism and postmodern writing with infinite possibilities of meaning. This contrast starts to become clear as he writes of the death of God.

The main contours of deconstructive a/theology begin to emerge with the realization of the necessary interrelation between the death of God and radical christology. Radical christology is thoroughly incarnational .... The death of God is the sacrifice of the transcendent Author/Creator/ Master who governs from afar. Incarnation irrevocably erases the disembodied logos and inscribes a word that becomes the script enacted in the infinite play of interpretation.

'Logos is a son ... Without his father, he would be nothing but, in fact, writing'.... By enacting the death of the tamscendent(al) Father/ signified, the word becomes the wayward, rebellious, erant 'son'.

(Taylor 1984:103, 106)

Taylor bases his view of traditional ontotheology on what he sees as the main Christian dualism or dyad which results in the suppression of one term of the dyad by the other. 
Most of the Christian theological network rests on a dyadic foundation that sets seemingly exclusive opposites over against each other. Furthermore, these paired opposites form a hierarchy in which one term governs, rules, dominates, or represses the other. For example, God governs the world, eternity and permanence are more valuable than time and change, presence is preferable to absence, spirit more worthy than body, etc. The grounding principle of this exclusive network is an abstract notion of identity, difference and non-contradiction'.

(Taylor 1984:108-109)

Taylor seeks to contrast this dyadic hierarchy (the ontotheological) with a free-playing, multivalent erring (the a/theological). The problem with Taylor's view is that there are a great many religious options available besides the ontotheological and a/theological dichotomy. We can follow this in the four notions developed in his Erring.

Taylor's first dichotomy is between God as the absolute Author/Creator/Master of ontotheology and the God incarnate of a/theology inscribed in writing which errs in an unending play of interpretations that marks the death of God in an eternal kenosis (Taylor 1984:19, 33, 97-120). Other options which he overlooks include God as. conceived by much process theology and naturalistic theism. Such a god would not be the absolute, isolated Master but would also not be marked by unfettered play, since the past character of God would provide a stable factor in the ongoing divine life. (This is William Dean's point in History Making History.) For our purposes we may adduthat Taylor also overlooks the possibility of a religious naturalism such as that of John Dewey, Henry Nelson Wieman, Mordecai Kaplan, or Samuel Alexander.

Taylor's second dichotomy is between the sovereign self in the image of the selfidentical, self-conscious, absolute God as Master and the notion of the self as an erratic trace, a generous communicant, able to take delight without possessiveness (Taylor 1984:34-51, 121-148). However; Taylor overlooks the variety of process-relational views of selfhood already developed, from Mead to Neville, which can do much of what be is groping for.

Taylor's third dichotomy is between history as a linear, logocentric, imaginative construction on the one hand, an attempt to deny death and overcome the despair of the unhappy conscience over the opposition between 'reality' and 'ideality' and on the other hand history as an endless erring, willing to affirm the real and breaking the power of the ideal, a purposeless erring which breaks the psychology of mastery and the economy of domination by spending generously. Erring is beyond good and evil, affirming the stance of carnival (Taylor 1984:52-73, 149-169). Again, Taylor overlooks the historicism of Gadamer or of Dean and others rooted in the early Chicago 
School which latter offers a non-logocentric of view of history, recognizes the presence of interpretation in the constriction of history, affirms a developing purpose, recognizes the reality of evil, having appropriate generosity, with changing and relative but real convictions about good and evil, and with community, not carnival, as its basic social metaphor.

Taylor's fourth dichotomy appears in his theory of meaning. Taylor rejects 'the book' as an ordered, logocentric totality, the author of which limits the proliferation of meanings, and truth as unified, singular, simple and abiding. The alternative is 'writing' as incessant erring, forever vague, without a foundation to anchor its proper meaning. Interpretation does not discover the correct meaning, but forever produces new ones (Taylor 1984:151). Once again there is at least one major view which Taylor ignores. The pragmatic view sees meaning as plural but not infinite, the process of inquiry not as erring but as developing criteria of adequacy without needing secure foundations, and interpretation as productive yet constrained by past links in the chain of interpretations. Related to the pragmatic is a radical empiricist use of sensitive discernment which also takes us beyond the dichotomy of objectivity and subjectivity, offering another option in addition to Taylor's alternative of a correct meaning anchored in a logocentric foundatinalism and an infinite play of meanings. The conclusions of such inquiry will have neither apodictic certainty nor be infinite erring, but rather tentative and minimal convictions, provisional and yet truths seen clearly enough and held strongly enough to live and to die by. (See also Wentzel Van Huyssteen's forthcoming book.)

The overall difficulty I have with Taylor is that he ignores most of the viable options in present-day religious thinking. He dismisses a traditional view of God, with which many of us have problems anyway, identifies this with both rationality and suppression, and then goes on to the opposite exreme of apparent irrationality and arbitrariness. Both poles of this dichotomy are unattractive. Taylor neglects a whole range of options, including religious naturalism.

One more point is to be made about Taylor. He affirms that axiological transcendence results in perpetual discontent and furthermore is a sign of a hatred of all that perishes.

The quest for truth represents a futile effort to escape the world of appearances and to discover (or uncover) the fugitive transcen-dental signified. In spite of protests to the contrary, this pursuit is never disinterested. 'The will to truth' simultaneously expres-ses 'hatred for all that perishes, changes, varies' and gives voice to a longing 'for a world of the constant'. 
This is to accept Nietzsche's view too uncritically. A will to truth is not necessarily a hatred of the perishing. It is a longing to understand the perishing, the changing, and the varying in order to understand and perhaps to love them more adequately and more fully. The will to truth need not be Nietzsche's image of Platonic transcendence of the finite. It can be rather a love of the perishing, changing, and varying which seeks to transcend, not the finite, but our erroneous understandings of it.

Here again, for Taylor it seems that you either love everything or hate everything. But are there not some things worth transforming. Are ignorance, prejudice, disease, and hatred worth contending with? While being this-worldly, must we wallow in everything? To love the finite does not mean to accept it without change. That way lie the worst excesses of Hindu civilization, as Aurobindo (1957:578-579) clearly saw. If suppression to be removed, as Taylor thinks, then that is one thing that is unacceptable. Therefore we cannot simply accept the finite. Let us grant that there has been much suppression, including suppression by nice Christians or by nice liberal people. The cure, however, is not to accept anything. Between toleration of everything, including evil, and the rejection of all things except one's parochial notions, there lies a vast range of options where we must exercise responsible decisions.

\section{PHILIP HEFNER}

The central concept of Philip Hefner's book, The Human Factor, is his created cocreator theory: people are the

created co-creators whose purpose is to be the agency ... to birth the future that is most wholesome for the nature that has birthed us ... our own genetic heritage ... (and) the entire human community and the evolutionary and ecological reality in which and to which we belong. Exercising this agency is ... God's will for humans'.

(Hefner 1993:27)

My way of stating Hefner's overcoming of the traditional dichotonies is that he offers a strong triple thesis: a) methodologically, science is an essential component for doing theology, b) ontologically, there is a kinship between humans and the rest of creation, c) practically, the'meaning and purpose of human existence is to fulfill the whole ecosystem. I call this a strong thesis because he has integrated the theological and the scientific dimensions of his work in a tighter synthesis than almost any other theologian past or present. 
Methodologically, theology is not on track, nor God rightly obeyed nor the spiritual life understood unless we try to study the processes of nature and their future.

Ontologically, nature has a central place in Hefner's theology. Nature is the medium of both the knowledge of God and of the grace of God. 'Encounter with God takes place within the processes of nature' (Hefner 1993:45). The evolutionary process, including the mechanism of natural selection, is God's process of bringing into being a creature who is a more complex phase of freedom. The evolutionary matrix is 'the work of God to allow for the emergence of that which is necessary for the fulfillment of God's intentions' (Hefner 1993:45).

Our secular and religious traditions are both ambiguous about the 'nonnegotiable message of the sciences that we are part and parcel of nature' (Hefner 1993:69). Some aspects of the tradition, the doctrines of the Holy Spirit and the sacraments, for example, predispose us to accept this message, but they are balanced with aspects that speak dualistically of humans as different from nature.

This kinship of humans the rest of creation is seen very clearly just at the point where the distinctiveness of humans is delineated. The biocultural sciences show us that humanity is composed of the point of two information streams, the genetic and the cultural. 'Homo sapiens is a two-natured creature, a symbiosis of genes and culture' (Hefner 1993:102). Indeed no theologians in my reading has studied so much genetics nor integrated it so tightly into his theology.

An implication of this emphasis on kinship with the natural is found in Hefner's treatment of freedom. Conditionedness and freedom have co-evolved and constitute the evolutionary basis for morality. The evolution of the central nervous system brings in the biological basis of morality, namely, choice, feedback, and response to feedback. The legacy bequeathed to us, our 'capacities for thought-out action, interpretation, and justification' are part of being created and also a co-creator (Hefner 1993:100). In addition to these inherited capacities, of course, we are also a product of our co-creating of images. Finally the practical point is that the human purpose is to contribute further to the wholesomeness of natural processes.

The purposes for which God has intended the freedom and co-creatorhood of the human species pertain ... to the entirety of the process of evolution and the terrestrial ecosystems .... Human culture is ... a possible instrumentality for the fulfillment of the divine purposes for both humans and the rest of the created order on earth.

(Hefner 1993:48) 
Hefner suggests that this is the most far-reaching conclusion of the book in its rearrangement of the images that govern our perceptions. We often think of human purposes in terms of obedience to God's will or in terms of upbuilding the human community: love, justice, et cetera. But human fulfillment must be defined within the larger framework of the natural order. 'The direction God-ward leads us reflexively to nature' (Hefner 1993:60). In technical terms, we need a noninstrumental valuation of nature. In theological terms Jesus' life and death have intrinsic value, as do the elements of the sacrament of communion: this can be a model for our seeing intrinsic value in nature.

Our responsibility to the rest of nature is parallel to our responsibility to our children. We do not mold them to become what we want them to be, but rather we contribute what will provide the greatest possibility for wholesome future. 'If nature is God's great project, then by devoting ourselves to its care and redemption we are pouring our resources into the same effort' (Hefner 1993:74). Other creatures are more essential to the ecosphere than humans; humans are unique in that they self-consciously make decisions which effect the rest of the ecosphere (Hefner 1993:119).

Hefner seeks a middle position between a quest for certainty and epistemological nihilism. Hefner's conception of the testability of theories is one area where he strives for his middle position of the relatively reliable and tentative.

Hefner draws heavily on the tradition of Popper and even more of Lakatos that a good theory needs to be falsifiable. Hefner's way of making this criterion flexible is that the 'theory is a set of concepts that is capable of interpreting a range of phenomena. This set of concepts must meet satisfactorily two further criteria: first, it must in pinciple be falsifiable, and second, it must be fruitful for stimulating further thinking and interpreting new data' (Hefner 1993:258). In clarifying this concept Hefner adds: 'Obviously, theological statements do not aim at empirical content with the same degree of precision that scientific statements do, nor do they prize prediction in the way that scientific discourse does .... I suggest that theological statements ... must be potentially falsifiable - that is, they must have a class of potential falsifiers that is not empty. How full that class is, is subject to variation, case by case. Theology's success in extending its explanatory field is directly correlated to how full or empty its class of potential falsifiers is' (Hefner 1993:259). 'It is critical that the import of any faith proposal be clear so that its significance can be assessed even if it is not easily tested' (Hefner 1993:15).

The theory of the created co-creator is 'a candidate to be considered as theory ... a hypothesis to be tested .... A theory cannot be demonstrated with finality ... even though it can be falsified. It is considered to be viable or useful so long as the attempts 
to falsify it (or test it) are productive for our understanding'. We check to see if it possesses explanatory power, that is, gives 'us comprehension of a large body of data that otherwise would be raw and uninterpreted' (Hefner 1993:18).

'Christian faith does not ordinarily speak of its insights and their theological elaboration as theories to be tested or falsified .... To the human community at large, however, as well as to the reflective members of the believing community, even revelation is a theory to be tested' (Hefner 1993:18). Hefner uses the term 'falsifiability' to indicate that 'theological theories should be referred to the world of possible experience and that it is desirable to discern what a proposed theory negates as well as what it affirms' (Hefner 1993:24).

'The Lakatosian appeal to fruitfulness (is) ... a welcome proposal for enabling public discussion of important issues' (Hefner 1883:27). Hefner speaks of testing hypotheses in a less than formal and rigorous way, as seeing if they 'make sense of what is known'. 'Hypotheses in theology should ... meet Popper's two criteria of falsification - that the acceptance or rejection of the hypotheses should be grounded in correlations with or deviations from knowledge drawn from the world of possible experience, and that the discussion of the adequacy or inadequacy of the theological hypothesis should be carried out in publically available discourse' (Hefner 1992:28).

It is helpful to note that for Hefner the essence of testability is not predictive power but rather the drawing of specific implications on a lower level of abstraction to be subject to public scrutiny. This scrutiny can be to determine the accuracy and adequacy of these implications or their usefulness in understanding an area of life. Testing can even be done by reference to an entire body of relevant scientific literature (Hefner 1993:41, $42,45,48)$. 'What is at stake in the falsification of theological theories' is whether in public scrutiny they 'lead to interpretations of the world and of our experience in the world that are empirically credible and fruitful - that is, productive of new insights and research' (Hefner 1993:261). A fuller elaboration of Hefner's theory of falsification would involve his Lakatosian distinction between core and auxiliary hypotheses, it being the latter which are subject to falsification.

In this entire discussion of testability, Hefner is drawing a middle position between a quest for certainty and a despair of finding any good reasons. His remark concerning one hypothesis can stand for his view of them all. When these theories are subject to public scrutiny, 'even though scientifically certain consensus may not be possible, not all such proposals are equally valid' (Hefner 1993:41).

We have seen that Hefner's approach to testability of theories is an area where his search for relatively reliable, tentative theories seeks to avoid the choice between a quest for certainty and epistemological nihilism. A further area of search for the tentatively reliable is his study of myth and ritual, a key component of his theory. There are two levels of tentativeness here. 
The first level of tentativeness is that even though 'cultural information in the form of myth concerns that about which we cannot speak with certainty', it is necessary information (Hefner 1993:186). Humans need to know whether the nature of reality is such that hard work and commitment make sense, whether love beyond the kinship group, which is costly and often not pleasurable, is justified on the grounds that it is commensurate with the fundamental character of reality. Myths are information packets about the nature of reality. Underdetermination by the data is often cited as grounds for dismissing myth and ritual. However, in their early history 'humans faced the necessity of acting on the basis of cultural information in circumstances that hardly allowed for hypothesis formation and testing'. Myth provided precisely this kind of information. 'Humans still require this kind of information about the nature of things, and they inust act upon it even before they can gather data for demonstrating or falsifying it'. 'We cannot hold the behavioral consequences of myth and ritual in abeyance until such time as we have them recast in more credible intellectual form. Humans require the motivational dimensions as urgently as they need conceptual adequacy' (Hefner 1993:204-205). Since such information is necessary, by implication it has some degree of reliability. Finally Hefner comes to the theological point that the love command is to be understood within the myth-ritual-praxis complex which he has elaborated.

The second level of tentativeness of Hefner's treatment of myth and ritual is that he develops his own discussion of myth and ritual by a detailed reference to several recent studies of prehistoric cave art. In recognizing the conjectural character of these interpretations he explicitly recognizes the tentative character of his own interpretation of this art.

Hefner is not a foundationalist. Yet science, especially genetics and evolutionary biology, is crucial in that it opens up 'new vistas for understanding human existence' (Hefner 1993:16). Unlike extreme antifoundationalism, Hefner gives science an important role in understanding humans.

It is not that 'science determines what may or may not be believed religiously'. Rather whether a traditional religious symbol is enhanced or rendered obsolete when juxtaposed to science depends on whether that symbol renders significant human experience, including science, adequately (Hefner 1993:141). In short, what we need is scientifically informed discussion.

The role science plays for Hefner can be illustrated by his discussion of trans-kin altruism. 'Humans face a distinctive evolutionary challenge ... (They) must live cooperatively in large communities of persons who are not kin relatives - that is, who are genetic competitors (Hefner 1993:198). Hefner focuses on the question formulated by E.O. Wilson. How can altruism towards people not kin, which reduces personal fitness, possibly evolve by natural selection? 
From the first moment that I read Wilson, I felt that a religious tradition that centers on a man dying on a cross for the benefit of the whole world could not responsibly ignore a scientific discussion about the emergence within the evolutionary process of the possibility of living viably so as to put the welfare of others so high on the agenda that one creature would put its own welfare in jeopardy for the sake of others.

(Hefner 1993:191)

Hefner's answer to Wilson's question is that the ancient myths and rituals that carry the cultural information packets for trans-kin altruism possess reliable information. Even though they are blatantly underdetermined by the data, can be subjected to reasonable processes of falsification only with difficulty and even appear to be falsified in the light of contemporary science, they continue to serve the survival and flourishing of human communities. Indeed, even in secularized societies, the usefulness of myths and ritual, in modern as well as ancient forms, is far from being eliminated.

We should think of 'a reciprocal impact, which consists both of mutual critique and possible reinforcement' between ancient information systems of myths and rituals and scientific theories (Hefner 1993:195). In fact, there are three nodes of reflection appropriate to the study of trans-kin altruism: 'the biocultural evolutionary sciences, the study of myth and ritual in human evolutionary history, and theology' (Hefner 1993: 196). Indeed, part Four of his book is a detailed elaboration of these three.

In light of this discussion, Hefner's postfoundational vision of the role of theology can be sumnarized thus:

Theology is motivated by its innate thrust to interpret reaches of experience that extend outside the formative events of the community of faith ... to provide genuine knowledge of wider human experience .... The created co-creator theory is intended to enable (such) an extension of the explanatory power of Christian faith.

(Hefner 1993:258)

The interplay of science and theology means that no one discourse is privileged and both myth and discursive language are valorized. Today, science and myth/ritual must function together to provide the information that will serve the natural order, and us humans within it, as we struggle under survival-threatening conditions. Science sets forth the fundamental descriptions of our human teleonomy, but myth and ritual that make the basic proposals concerning the direction, meaning, and purpose of the struc- 
tures and processes whose fulfillment shapes the form of human being. We need both to trust 'in the good sense of myth and ritual, on their own terms, and also in our good sense to appropriate or reject them critically' (Hefner 1993:216).

\section{DELWIN BROWN}

The 'constructive historicism' which Delwin Brown sets forth in his Boundaries of Our Habitations may be read as offering: 1) the construction of a theory of the nature of cultural traditions, drawing on both historical and conceptual studies, and 2) two theological implications, (a) a proposal for the future directions of theology and (b) a critique of major types of contemporary theology.

Brown's theory of cultures is that they are polyphonic collections of fluid and diverse meanings yet specific enough so that individual and communal identities may be negotiated within their fields. Cultural traditions are characterized by both variety and change. A tradition is a 'continuously reformed and formative milieu ... a dynamic stream of forces' (Brown 1994:4). It should be noted that this theory is designed to avoid the extremes on the one hand of an essentialism which allows for no plurality nor for change and on the other of a view which sees cultures as basically chaotic phenomena. Cultures, traditions, and subtraditions have boundaries, but these boundaries 'are always flexible (revisable from within) and porous (permeable from without') (Brown 1994:201). They are more analogous to galaxies than to stars or constellations.

Within cultural traditions Brown finds that there frequently is a canon, an authoritative locus. While the canon might be textual, it is often a complex of ritual myth or narrative.

The very notion of a canon suggests foundationalism and a focus on the stable. However, Brown suggests two points which prevent his view from being carried to this extreme. 1) The identities of a tradition can be created and recreated through rearrangement within a canon and also through rearrangement of a canon. In other words change may occur either within the canon or as a change of the canon itself. 2) The relationship between a canon and a tradition is dialectical. 'Tradition creates canon and canon creates tradition. A corollary is that each is fluid' (Brown 1994:29).

Throughout all of this Brown focusses on neither abstraction nor concreteness, stability nor change, singularity nor plurality, but on a reciprocity between them. 'In particular, we can learn to think again of a tradition as a continuously reformed and formative milieu, as a dynamic stream of forces in which we live (or die), move (or stagnate), and gain (or lose), our being' (Brown 1994:4).

Brown self-consciously sees his own work as the avoiding of 'deleterious dualism' as he calls them (Brown 1994:x). He sums up his theory of cultural tradition in ten claims which he calls provisional proposals, hypotheses to be tested, again avoiding the extremes of foundationalism and episternological nihilism (Brown 1994:25-29). 
Further he views all theorizing, including his own, as partially or temporarily true or adequate.

Theorizing always falsifies in a sense, for even the best theories fail to capture the depth and complexity of the data .... Even theories judged to be true are so only for a time; they are not true, or even interesting, for eternity. But eternity is not where we live. A theory useful for a while is as useful as a theory can be.

(Brown 1994:58)

Brown's critique of recent theology follows from this. Brown sees Clark Pinnock and George Lindbeck as both developing conservative theologies. While he holds them to be 'two different, important, and in certain respects, quite original thinkers' (Brown 1994:120), he finds that both make the same assumption about a canon (Brown 1994: 125).

Conservatism's fear that the identity of tradition might be lost, usually cast as a concern about a 'heresy', is misguided. Conservatism underestimates the power of the canon ... to define itself in each new circumstance. Therefore, conservatism presumes to become the guardian of tradition, defining the boundaries of its resources and the possibilities of its permutations.

(Brown 1994:127)

The problem with radical theologies (here Brown discusses Mark C Taylor) is that they neglect the power and the truth of tradition. Brown treats Ogden, Reuther, Kaufman and Cobb as representatives of liberal theology. 'Each of these liberal positions is significantly different .... Yet all identify some core, some element or elements, as the interpretive center of Christian faith. That, certainly, is not problematic. But what usually follows in liberalism is: the virtual disappearance of the remainder of the Christian symbolic complex' (Brown 1994:135). 'As a result liberal theology is in grave danger of becoming in disguise what radical theology is openly - creativity without the substance of inherited symbols. The result would be the same: conclusions that are important, but culturally and religiously ineffective' (Brown 1994:137).

Hence Brown's recommendations for theology follow. We need a revisionary and publicly debatable option beyond tbe essentialism of both conservative and liberal theologies and the anti-essentialism of many radical aad deconstructive theologies. There are no universal rules for theology, but it does not follow that all criteria are 
always strictly local, entirely intrasystematic. 'Many criteria are common to sets of varied perspectives' (Brown 1994:5). The disciplines of cultural and anthropology and the history of religions will 'establish restraints that discipline theological claims, and sometimes, effectively (even if never finally) accredit or discredit them (Brown 1994: 11).

Theology should return to traditions. Not, of course, to traditions as they were understood by the Enlightenment mentality that uncritically dismissed them or by the counter-Enlightenment mind that uncritically embraced them, but to traditions as they persistenly show themselves to be - dynamic and diverse streams of being and meaning .... Theology should be tbe critical analyst and creative conveyor of the vast conceptual resources, actual and potential, of religious traditions. In thus critically and creatively reconstructing the past, a theology is a tradition's caregiver.

(Brown 1994: 137-138)

An important aspect of Brown's sidestepping of 'deleterious dualisms' is his conceptualization of abstract analysis and the affective dimensions as end points along a continuum: In line with this he stresses ritual as a crucial, not the exclusive, but a crucial element in a tradition.

\section{Works consulted}

Aurobindo, S 1957. Arya, in Sarvepalli, R Moore, C A, A Sourcebook in Indian Philosophy. Princeton: Princeton University.

Brown, D 1994. Boundaries of Our Habitations: Tradition and Theological Construction. New York: State University of New York.

Dean, W 1988. History Making History: The New Historicism in American Religious Thought. Albany, New York: State University of New York.

Hefner, P 1993. The Human Factor: Evolution, Culture and Religion. Minneapolis: Fortress.

Lindbeck, G 1984. The Nature of Doctrine: Religion and Theology in a Postliberal Age. Philadelphia: Westminster.

Stone, J 1992. The Minimalist Vision of Transcendence: A Naturalist Philosophy of Religion. Albany, New York: State University of New York.

Taylor, M C 1984. Erring: A Postmodem A/theology. Chicago: University of Chicago. 